\title{
Influence of Applying Preventive Health Conditions Strategy during Coronavirus Pandemic in KSA
}

\section{Sherifa Mostafa M. Sabra}

Asst. Prof., Dr., Microbiology, Technology and Science Dept., Ranyah University College, Taif University, KSA

Corresponding Author: Sherifa Mostafa M. Sabra. Asst. Prof., Dr., Microbiology, Technology and Science Dept., Ranyah University College, Taif University, KSA.

Received date: December 13, 2020; Accepted date: December 15, 2020; Published date: January 02,2021

Citation: Sherifa Mostafa M. Sabra (2021) Influence of Applying Preventive Health Conditions Strategy during Coronavirus Pandemic in KSA J, Biotech. and Bioprocessing 2(1); DOI: 10.31579/2766-2314/014

Copyright: (C) 2021, Sherifa Mostafa M. Sabra, This is an open access article distributed under the Creative Commons Attribution License, which permits unrestricted use, distribution, and reproduction in any medium, provided the original work is properly cited.

\begin{abstract}
This research was for "Influence of Applying Preventive Health Conditions Strategy (PHCS) during Coronavirus Pandemic (CVP) in Kingdom of Saudi Arabia (KSA)". The target was through questionnaire to individuals in KSA. That application of PHCS and persons contribution accountable establishments, to cover Coronavirus infection (CVI), caused CVP and control to redact it, numbers to maintain Saudi health (SH). Using "Crosssectional Study Method", were on Network for survey study in Saudi community (SC), collected data and had analyzed. Remained $99 \%$ participants to questionnaire about everyone, remained $89 \%$ dedicated to smearing PHCS closely a total. It was $100 \%$ reinforced PHCS, that $98 \%$ had approving support non-compliance PHCS. As stayed $83 \%$ stationary numerous parties from their doings, and was $100 \%$ all individuals, braked family visits in anticipation of any CVI. That stared $85 \%$ immobile market exit except for about individuals since it was a need to achieve family responsibilities, and others dedicated at home to decrease CVI. Experiential 74\% produced the PHCS to have injury in three quarters because of discontinuing the numerous doings. Here $26 \%$ originated that a quarter of persons had cases of CVI, where $55 \%$ the relations applied the PHCS about partial because of the attendance of people with the similar family. That concluded the results showed the existence of the PHCS importance in the existence and importance of the CVP. The extent to KSA individuals helped to reduce CVI and protect SH. That recommended PHCS position to SH reserve, deliver a fit culture, and reinforce persons for their help.

Keywords: applying preventive health conditions strategy, coronavirus pandemic, coronavirus infection, saudi health, cross-sectional study method, saudi community
\end{abstract}

\section{Abbreviations list}

CV: Corona Virus, CVI: Coronavirus infection, CVP: Coronavirus pandemic, KSA: Kingdom of Saudi Arabia, PHCS: Preventive Health Conditions Strategy, SH: Saudi health, SC: Saudi community.

\section{Introduction}

Before the first long-established case of CVI in the Kingdom of Saudi Arabia (KSA), the national authority closed shopping centers and suspended flights, face-to-face teaching and bodily presence at most government area as prevention stages [1]. CVI in KSA considered risk, severe repression events occupied meanwhile February, close of Mecca and Madinah, end of cultural events, and mass gatherings. During February and March: Umrah postponement, annulment and generous proceedings limit; educational organizations closure; sport rivalries and proscription postponement of social events; spending malls, eateries, coffee workshops, community gardens closure; postponement of daily and Friday mosques prayer; suspension of public transport, flights, trains, buses and taxis; partial restriction [2]. Holy shrines closure was one of the bold choices government taken, was important for the mitigation of CVP [3]. That similar meanings, can highlight the bodily parting or distance between healthy and diseased persons with confirmed or CVI [4]. Saudi Arabia's use of skill interferences to combat CVP, which used for contact tracing and surveillance [5]. Social coldness, self, home-isolation, have been presented as possible protective ladders applied to limit, delay or crush the imitation CVI rate [6]. Saudi Arabia's repression plan emphases on both extenuation and conquest methods together with technology interferences to stop CVI spread [7]. Health establishments left with only preventive events to CVI challenge [8]. In KSA during 2020, overall implementation of social estrangement was satisfactory, $37.8 \%$ were never sendoff home during the stay-at-home period. Better devotion to social estrangement observed [9].

The target of this research was through the questionnaire, to individuals in the KSA. That followed up through the implementation of the PHCS and the individuals assist the responsible authorities. As to contain the CVI, which caused CVP and control to redact the CVI, numbers to maintain the $\mathrm{SH}$. 


\section{Materials and Methods}

Using the "Cross-sectional Study Method" [10], preparation of "Questionnaire" that included the paper items (Table1); [11]. Conducting the questionnaire through Network for survey study in SC [12]. Gathering the questionnaire survey data [13], the data analysis were using "Excel Set" which formed the consequences [14].

\begin{tabular}{|c|c|c|c|}
\hline *No & $* \mathbf{Q}$ & \multicolumn{2}{|c|}{ *A } \\
\hline 1 & You present in Kingdom of Saudi Arabia during the Coronavirus pandemic & Yes & No \\
\hline 2 & Dedicated to applying the preventive health conditions strategy in Kingdom of Saudi Arabia & Yes & No \\
\hline 3 & Supporting preventive health conditions strategy in Kingdom of Saudi Arabia & Yes & No \\
\hline 4 & $\begin{array}{l}\text { Authorizing support non-compliance with preventive health conditions strategy in Kingdom of Saudi } \\
\text { Arabia }\end{array}$ & Yes & No \\
\hline 5 & $\begin{array}{l}\text { Standing studying or working to adhere the preventive health conditions strategy in Kingdom of Saudi } \\
\text { Arabia }\end{array}$ & Yes & No \\
\hline 6 & $\begin{array}{l}\text { Family gatherings stopping in agreement with the preventive health conditions strategy in Kingdom of } \\
\text { Saudi Arabia }\end{array}$ & Yes & No \\
\hline 7 & $\begin{array}{l}\text { Stationary going out to markets and malls in accordance with the preventive health conditions strategy } \\
\text { in Kingdom of Saudi Arabia }\end{array}$ & Yes & No \\
\hline 8 & $\begin{array}{l}\text { Adhering to the preventive health conditions strategy in Kingdom of Saudi Arabia causing any material } \\
\text { or moral damages }\end{array}$ & Yes & No \\
\hline 9 & $\begin{array}{l}\text { There are cases of Coronavirus infection in the family despite adherence to preventive health conditions } \\
\text { strategy in Kingdom of Saudi Arabia }\end{array}$ & Yes & No \\
\hline 10 & $\begin{array}{l}\text { Appling the preventive health conditions strategy in Kingdom of Saudi Arabia at home due to the } \\
\text { presence of a case of Coronavirus in the family }\end{array}$ & Yes & No \\
\hline
\end{tabular}

Table 1: Questionnaire of applying *PHCS during *CVP in KSA

\section{Results and discussion}

\begin{tabular}{|c|c|c|c|c|c|c|c|c|c|c|}
\hline$* \mathbf{Q}$ & Q1 & Q2 & Q3 & Q4 & Q5 & Q6 & Q7 & Q8 & Q9 & Q10 \\
\hline$* \mathbf{A}$ & $99 \%$ & $89 \%$ & $100 \%$ & $98 \%$ & $83 \%$ & $100 \%$ & $85 \%$ & $74 \%$ & $26 \%$ & $55 \%$ \\
\hline
\end{tabular}

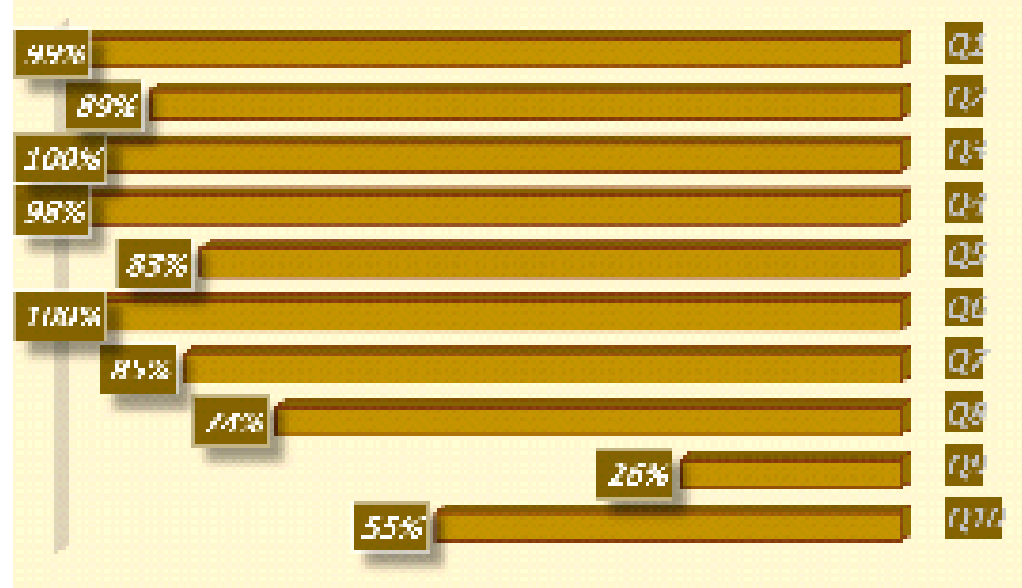

Table 2 and Graph 1: Prevalence of applying *PHCS during *CVP in *KSA

Table 2 and Graph 1 reading prevalence of applying PHCS during CVP in KSA, the first question, "You present in Kingdom Saudi Arabia during the Coronavirus pandemic", the answered by the $99 \%$ participants to the questionnaire about everyone. It indicated the importance of the PHCS and indicated that the participants are citizens and residents during the CVP in KSA. The second question, "Dedicated to applying the preventive health conditions strategy in Kingdom of Saudi Arabia", was 89\% participants adhered to the PHCS nearly a total, which was not applied by about tenth individuals, indicated caution in the PHCS. Individuals may be important bodies in society or help to protect the $\mathrm{SH}$ to help reduce CVI [1-2]. The third question, "Supporting preventive health conditions strategy in Kingdom of Saudi Arabia", it was found $100 \%$ all participants supported the PHCS in order to disrupt the infected and not transmit the CVI to healthy others, which harms individuals and the SH [1-2]. The fourth question, "Authorizing support non-compliance with preventive health conditions strategy in Kingdom of Saudi Arabia", that 98\% individuals agreed to penalties for individuals who have not implemented the PHCS, as it was important to reduce CVI and limited the spread of it in the $\mathrm{SH}$ [1-3]. The fifth question, "Standing studying or working to adhere the preventive health conditions strategy in Kingdom of Saudi Arabia", found $83 \%$ stopped the various parties from their activities. That was covered the community, others may be individuals working in the 
forms that need to be present to protect the community, and it found that most of them made the arrest to reduce CVI [1-3]. The sixth question, "Family gatherings stopping in agreement with the preventive health conditions strategy in Kingdom of Saudi Arabia", was 100\% all individuals stop family visits in anticipation of any CVI or its transmission in the community and protection from CVI [3, 6-9]. The seventh question, "Stationary going out to markets and malls in accordance with the preventive health conditions strategy in Kingdom of Saudi Arabia", regarded 85\% stopped market exit except for some individuals because it was a necessity to work or perform family duties, and others have committed at home to reduce CVI [6-9]. The eighth question, "Adhering to the preventive health conditions strategy in Kingdom of Saudi Arabia causing any material or moral damages", watched $74 \%$ caused the PHCS to have damage in three quarters because of stopping the various activities. Individuals agreed to that even though their work was daily and they needed to cooperate with the PHCS to eliminate the spread of CVI [1-2]. The ninth question, "There are cases of Coronavirus infection in the family despite adherence to preventive health conditions strategy in Kingdom of Saudi Arabia", there 26\% found that a quarter of individuals have cases of CVI, using the PHCS reduced it by time to implement it to protect the $\mathrm{SH}[1-2,4-5]$. The tenth question, "Appling the preventive health conditions strategy in Kingdom of Saudi Arabia at home due to the presence of a case of Coronavirus in the family", where 55\% the families implemented the PHCS about half because of the presence of people with the same family. That were in order to reduce the spread of CVI in the family or outside the family, which helps the SH with all individuals in KSA [6-9]. The PHCS issued locally and internationally by the competent places to contain and reduce the CVI. Because of implementing the PHCS issued and the cooperation of individuals, whether citizens or residents, and in the various sectors and bodies in the KSA. This led to the stability and reduction of the number of CVI. Despite what it caused in the standards or the material and moral effects, it also reduced travel and the arrival of some individuals to their families and the enjoyment of vacations. This was a result of the entire period of caution and the application of the PHCS, as the presence of some individuals and families, whether citizens or residents, in the KSA for a period of approximately one year, which made individuals' fear of CVI and the cooperation of individuals in implementing measures. PHCS helped reduce CVI, individuals sacrificed holidays in exchange for preserving conditions and minimizing CVI. This evidenced by the statistics of CVI in KSA, and it showed that the numbers reduced and the numbers are stable [1-2, 6-9].

\section{Conclusion}

That concluded the results showed the existence of the PHCS importance in the existence and importance of the CVP. The extent to which individuals in the KSA helped to reduce CVI and protect $\mathrm{SH}$.

\section{Recommendations and further study}

That emphasized the importance of the PHCS to preserve the SH, provide a healthy culture, and strengthen individuals for their assistance. That hope will do the next research in following up the existence of the PHCS and the extent of eliminating the presence of the CVI in the KSA.

\section{Acknowledgments}

Distribution thanks to all the review persons donated to the survey and replying to crop this investigation.

\section{References}

1. Algaissi, A., Alharbi, N., Hassanain, M., Hashem, A., (2020). Preparedness and response to COVID-19 in Saudi Arabia: Building on MERS experience. J. Infect. Public Health, 13(6):834-838.

2. Yezli, S., Khan, A., (2020). COVID-19 Social distancing in the Kingdom of Saudi Arabia: Bold measures in the face of political, economic, social and religious challenges. Travel Med. Infect. Dis., 101692.

3. Ebrahim, S., Ziad, A., (2020). COVID-19, the role of Mass Gatherings. Travel Med. Infect. Dis., 34:101617.

4. Singhal, A., (2020). Review of coronavirus disease-2019 (COVID-19). Indian J. Ped., 87:281-286.

5. Benny, J., (2020). Saudi Arabia's technology investments pay off in coronavirus battle.

6. Center for Disease Control and Prevention. Coronavirus Disease 2019 (COVID-19), (2020).

7. Fahad, A., Anan, A., Seham, A., Hebah, A., Hayat, M., et al (2020). A comparative study on the strategies adopted by the United Kingdom, India, China, Italy, and Saudi Arabia to contain the spread of the COVID-19 pandemic. J. Healthcare Leadership, 12.

8. Sen-Crowe, B., McKenney, M., Elkbuli, A., (2020). Social distancing during the COVID-19 pandemic: staying home save lives. Am. J. Emerg. Med., 2020.

9. Abdu Aldarhami, B., azaid., Omar, A., Naif, B., (2020). Public perceptions and commitment to social distancing "Staying-atHome" during COVID-19 pandemic: A national survey in Saudi Arabia. Int. J. General Med., 13:677-686.

10. Lee, J., (1994). Odds Ratio or Relative Risk for Cross-Sectional Data? Int. J. Epidemiology, 23(1):201-3.

11. Smedts, P., de Vries, H., Rakhshandehroo, M., (2009). High maternal vitamin $\mathrm{E}$ intake by diet or supplements is associated with congenital heart defects in the offspring. BJOG, 116(3):41623.

12. Groves, M., Fowler, J., Couper, P., Lepkowski, M., Singer, E., Tourangeau, R., (2009). Survey methodology. New Jersey: John Wiley and Sons. ISBN 978-1-118-21134-2.

13. Bethlehem, J., Biffignandi, S., (2012). Handbook of Web Surveys. Wiley Handbooks in Survey Methodology. 567. New Jersey: John Wiley and Sons. ISBN 978-1-118-12172-6.

14. Şeref, H., Ahuja, K., Winston, L., (2007). Developing spreadsheet-based decision support systems: Using Excel and VBA. Dynamic Ideas. ISBN 978-0-9759146-5-6. 